\title{
THE RELATIONSHIP BETWEEN A LYSOZYME-LIKE ENZYME AND FROG ADENOCARCINOMA*
}

\author{
George W. Nace, Tadakazu Suyama, $\uparrow$ Takuzo Iwata \\ Department of Zoology, The University of Michigan \\ Ann Arbor, Mich.
}

The occurrence of macromolecular change accompanying differentiation in embryonic or neoplastic development is well recognized, even if poorly understood..$^{1-5}$ In the course of immunochemical studies on macromolecular changes related to differentiation in the amphibian, ${ }^{6-8}$ we have had occasion to examine the antigenic composition of the frog kidney and of the frog renal adenocarcinoma, which is believed to be of viral origin." 10 The following is a report of observations on antigenic differences between the normal and tumor kidney of the frog, on the possible identity of one of these antigens, and on some differences between tumor-susceptible and resistant frogs. ${ }^{11-13}$

\section{Materials and Methods}

Antigens. Rana pipiens obtained from Alberg, Vt., were used as the source of embryos, normal organs, and tumors, from which "supernatant" fractions were prepared ${ }^{i 4,15}$ at 0 to $4^{\circ} \mathrm{C}$. by homogenization from the frozen

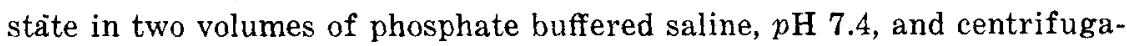
tion at $12,000 \mathrm{~g}$ for 20 minutes. These supernatants were used as injection or test antigens after adding merthiolate. Although all the renal adenocarcinomas were palpable, they were not of uniform histological character and it was impossible to be assured of complete separation of tumor from "normal" tissues.

The bacteriolytic enzyme described below was prepared from ovaries or larvae (Shumway Stages 19-23) because of the limited supply of normal kidneys. A bentonite adsorption procedure modified from the method for chicken egg white lysozyme was used. ${ }^{16}$ Ovaries from two to three frogs were ground in $80 \mathrm{ml}$. of 0.85 per cent $\mathrm{NaCl}$, adjusted to $p \mathrm{H} 4$ to 4.5 with acetic acid and rehomogenized, frozen and thawed three times, and centrifuged at $10,000 \mathrm{~g}$. The precipitate was reprocessed in $40 \mathrm{ml}$. of 0.85 per cent NaCl. The supernatants were pooled, filtered, adjusted to $p H 6.8$

*This work was supported by U.S. Public Health Service Research Grants GM 05409 and CA 06929 of the National Institutes of Health and the National Cancer Institute, respectively; and by Grant DRG-419 of the Damon Runyan Memorial Fund for Cancer Research, by Faculty Research Grants No. 34 and No. 441 of the Horace Rackham School of Graduate Studies, University of Michigan; and by American Cancer Society Institutional Grant IN-40.

$\dagger$ Drs. Suyama (1960-1962) and Iwata (1962-1964) were on leave from the Department of Pathology, University of Kanazawa Medical School, Kanazawa, Japan. 
with $\mathrm{NaOH}$, left overnight at $4^{\circ} \mathrm{C}$., and centrifuged. After adsorbing this supernatant with bentonite ( 10 per cent in 1 per cent $\mathrm{KCl}$ ), an eluate was collected with $0.5 \mathrm{M}$ phosphate buffer, $p \mathrm{H}$ 7.4. The next eluate, i.e., "avidin,"

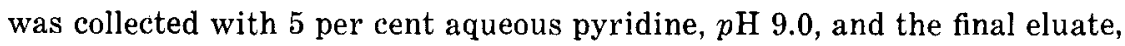
i.e., "lysozyme," collected with 5 per cent pyridine adjusted to $p \mathrm{H} 5$ with sulfuric acid.

The "Iysozyme" eluate was dialyzed in Visking casing against running tap and distilled water for 6 to 10 hours and then lyophilized. The yield varied from 50 to $80 \mathrm{mg}$. per $40 \mathrm{gm}$. wet weight of starting tissue, with a homogeniety of 70 to 90 per cent in the best preparations as estimated by agar gel electrophoresis.

The sources of preparations used for comparison with the Vermont materials were $R$. pipiens, $R$. clamitans, and $R$. catesbeiana, supplied by E. G. Steinhilber, Oshkosh, Wis.; and R. pipiens collected in Texas and Mexico, supplied by Carolina Biological Supply House, Elon College, N. C. Fresh kidneys from these animals were homogenized in phosphate buffered

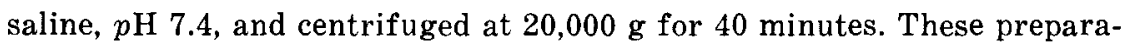
tions included five freezing-thawing steps, but did not include acid precipitation. They were used for quantitative intra-agar lysis tests without adding merthiolate.

Antisera. The antisera to be considered in this report were produced using antigens emulsified in Freund's complete adjuvant and injected into hybrid rabbits through intramuscular, intradermal, subdermal, and subscapular routes. ${ }^{15}$ Although single injections were usually sufficient, supplemental injections were given at irregular intervals for as long as two and a half years. Serum samples were collected ${ }^{17}$ at regular but increasing time intervals, merthiolated and stored at 0 to $4^{\circ} \mathrm{C}$. until used.

Agar diffusion and immunoelectrophoresis. Agar diffusion analysis on microscope slides followed a procedure developed in this laboratory. ${ }^{7.18}$ Immunoelectrophoresis ${ }^{19}$ was conducted in $70 \times 20 \times 6 \mathrm{~mm}$. blocks of two per cent agar. The antigens were dispersed in $0.05 \mathrm{M}$ veronal buffer, $p \mathrm{H}$ 8.6 , at $15 \mathrm{~V} / \mathrm{cm}$., $8 \mathrm{~mA}$ for 45 minutes at $4^{\circ} \mathrm{C}$. When relative migration data were desired, the zero point was determined by adding dextran to the antigenic mixtures.

After development of the serological diffusion patterns for four to seven days at $4^{\circ} \mathrm{C}$., the agar slices or planchets produced with our techniques were mounted, stained for protein, and photographed as appropriate. ${ }^{18}$ Unstained planchets were retained as controls.

Absorption procedures. The specific inhibition technique of Björklund ${ }^{20}$ was used to study the reactions of absorbed antisera in agar diffusion plates. This technique precipitates the "absorbed" antibodies in or immediately about the antibody well, whereas "unabsorbed" antibodies diffuse through the agar and form lines with the test antigens. Long diffusion 
periods with frequent observations were used to verify that lines would not form at control wells that contained the preparations used for absorption. Antisera to be used for immunoelectrophoresis were absorbed in vitro. Absorption was repeated if control tests revealed incomplete absorption.

Bacteriolytic activity. Initially, the occurrence of bacteriostatic activity in the frog preparations was observed and qualitatively assayed on plate cultures of Micrococcus lysodeikticus obtained through the courtesy of G. S. Fearnehough of the Department of Microbiology, University of Michigan. This activity was compared with the bacteriostatic action of commercial chicken egg white lysozyme. These assays were followed by quantitative tests conducted according to the turbidimetric procedure of Smolelis and Hartsell,"1 which utilizes $M$. lysodeikticus as substrate. The method was modified by preparing the commercial substrate (Difco Laboratories, Detroit, Mich.) suspensions in $1 / 15 \mathrm{M}$ phosphate buffer, $p \mathrm{H} \mathrm{6.2,} \mathrm{containing}$ 0.5 per cent $\mathrm{NaCl}^{2.2}$ When diluted to the desired concentration, $1 \mathrm{ml}$. of each test solution was mixed with $1 \mathrm{ml}$. of the substrate suspension (optical transmittance about 40 per cent), incubated at $37^{\circ} \mathrm{C}$. for varying periods of time, and measured spectrophotometrically at $540 \mathrm{~m}_{\mu}$. The preparations were compared using measurements obtained at 30 minutes incubation.

The turbidimetric tests were replaced by an intra-agar lysis technique designed to assay the lytic activity in the small quantities of reagents available from individual frogs and to reveal which line in electrophoresis or immunoelectrophoresis represented the material corresponding to the lytic substance. This technique resembles antibiotic assay procedures ${ }^{2: 3}$ and was adapted from a quantitative test for lysozyme designed by Amano. ${ }^{24}$ In his procedure the particulate substrate was suspended in agar that was drawn into a capillary tube and allowed to gel. Test preparations were compared with standard concentrations of lysozyme, which were allowed to diffuse into the tubes where they lysed the substrate in a length of each tube proportional to the concentration of the standard.

In our procedure, 1 to $2 \mathrm{mg} . / \mathrm{ml}$. of $M$. lysodeikticus substrate were suspended in the two per cent Difco Bacto-agar used for electrophoresis. To avoid the presence of the substrate in the strip of agar where electrophoresis occurred, the correspondence of the immunoelectrophoretic line with the region of lysis was examined by adding a strip of agar containing the substrate to both sides of the portion of agar in which the electrophoresis pattern was formed.

In quantitative applications a grid of cups was formed in sheets of two per cent agar poured in shallow glass-bottomed trays that could be sealed. An agar base layer $2 \mathrm{~mm}$. thick contained only the appropriate buffers and salts. This was overlaid by a $2-\mathrm{mm}$. layer consisting of the matrix agar to which the bacterial substrate was added. Standard concentrations of chicken egg white lysozyme were placed in one set of wells with the test 
TABLE 1

InTRa-AGar Lysis Tests of Frog Kidneys

\begin{tabular}{|c|c|c|c|c|}
\hline \multirow{2}{*}{ Animal } & \multicolumn{2}{|r|}{ August } & \multicolumn{2}{|r|}{ October } \\
\hline & Number & $\mathrm{U} / \mathrm{mgN} \pm$ s.d.* & Number & $\mathrm{U} / \mathrm{mgN} \pm$ s.d.* \\
\hline $\begin{array}{l}\text { R. pipiens } \\
\text { Vermont tumor }\end{array}$ & 3 & $911 \pm 418$ & 1 & 85 \\
\hline $\begin{array}{l}R . \text { pipiens } \\
\text { Vermont from nature }\end{array}$ & 11 & $8,640 \pm 3,715$ & 11 & $7,465 \pm 3,460$ \\
\hline $\begin{array}{l}\text { Oct.-Nov. } \\
\text { In laboratory }\end{array}$ & 4 & $\begin{array}{l}\text { Held at } \sim 25^{\circ} \mathrm{C} \\
13,219 \pm 4,675\end{array}$ & 6 & $\begin{array}{l}\text { Held at } 4^{\circ} \mathrm{C} \text {. } \\
10,914 \pm 5,570\end{array}$ \\
\hline $\begin{array}{l}\text { R. pipiens } \\
\text { Wisconsin }\end{array}$ & 10 & $14,870 \pm 5,196$ & 10 & $12,288 \pm 4,583$ \\
\hline $\begin{array}{l}\text { R. pipiens } \\
\text { Texas-Mexico }\end{array}$ & 10 & $6,477 \pm 3,420$ & 13 & $4,860 \pm 2,692$ \\
\hline $\begin{array}{l}\text { R. clamitans } \\
\text { Wisconsin. }\end{array}$ & 12 & $1,412 \pm 589$ & 9 & $1,235 \pm 1,088$ \\
\hline R. catesbeiana & - & - & 12 & $1,606 \pm 474$ \\
\hline
\end{tabular}

*Lytic units per mg. protein $\mathrm{N} \pm$ standard deviation. See the text for a description of the kidney homogenates used in these tests. 1,000 units = activity of $1 \mathrm{mg}$. of chicken egg white lysozyme. 6,250 units $\cong$ activity of $1 \mathrm{mg}$. protein $\mathrm{N}$ of chicken egg white lysozyme.

preparations in the other wells (FIGURE 14). After incubation for 10 hours at $37^{\circ} \mathrm{C}$., the lytic values of the frog test preparations were determined by comparing the diameters of the lysis discs around their wells with those of the chicken standard wells. This was facilitated by the linear relationship between standard disc diameters and concentrations (FIGURE 15).

The chicken standards were most readily prepared by weight and for convenience the activity of $1 \mathrm{mg} . / \mathrm{ml}$. was arbitrarily designated as 1,000 units of activity. The concentrations of the frog test preparations were determined as $\mathrm{mg}$. of protein $\mathrm{N}$ using serum albumin standards. It was not meaningful, therefore, to convert these to protein values. Thus the lytic values of the test preparations are given as units of activity per $\mathrm{mg}$. of protein $\mathrm{N}$. These values might be compared with 6,250 units, the activity of chicken egg white lysozyme on a per $\mathrm{mg}$. of protein $\mathrm{N}$ basis. However, since the commercial lysozyme standards contain considerable contamination ${ }^{25}$ and the frog kidney homogenates contain unknown quantities of contaminating proteins, this direct comparison of frog and chicken lytic activities is not justified. This does not detract from the technique as a 
measure to compare the lytic activities among the frog preparations since the extraction procedures were standardized as revealed by the fact that the different series of samples (TABLE 1) gave average protein $N$ values ranging from 0.97 to $1.07 \mathrm{mg}$. per $\mathrm{ml}$. with standard deviations ranging from 0.11 to 0.19 .

Controls that did not form lysis dises consisted of wells containing proteolytic enzymes (i.e., trypsin, collagenase, papain, and rennin) ; carbohydrases (i.e., chitinase and amylase); and esterases (i.e., propionate esterase , from which contaminating lysozyme had been removed by chromatographic techniques. Other controls included tests for the influences of various buffers, $p \mathrm{H}$ values, and salt concentrations.

\section{Results}

Analysis of antigens. Figures 1 to 6 illustrate the primary agar diffusion observations which led to this report. FIGUREs 1 and 2 show anti-NKS (antinormal kidney supernatant) tested against LAS (Lucké adenocarcinoma supernatant), NKS (normal kidney supernatant), AFS (adult frog serum), and TBS (tailbud supernatant). Unabsorbed antiserum was used for FIGURE 1. Particular attention is drawn to the line labeled $X$. Other lines in this and the other figures are labeled to permit reference to them in subsequent reports. The failure of line $X$ to coalesce with lines from the adjacent wells indicates that the appropriate antigen was absent from LAS and AFS. The deflection of line $X$ toward the LAS well in FIGURES 1 and 3 occurred because normal tissue had not been completely separated from the tumor used to make these preparations. The geometry of this pattern does not allow a determination of the presence or absence of line $X$ from the TBS pattern.

FIGURE 2 was produced following specific inhibition with LAS. No lines remain in the reaction with LAS or AFS, while line $X$ is still present in the reaction with NKS. A single line remains in the reaction with TBS. The characteristics of this line in FIGURE 2 and its coalescence with the NKS line in patterns not illustrated here identify this as line $X$.

FIGURE 3 was produced following specific inhibition with AFS. Line $X$ is clearly absent from the pattern produced by AFS, but it was reduced in intensity at the other wells. This suggests the presence of the antigen in low concentrations in the frog serum, but indicates that it is not a serum protein contaminant of the organ preparations.

In FIGURES 4 to 6 , anti-LAS was used in place of anti-NKS, but the antigens and the geometry remained as in FIGUREs 1 to 3 . Figures 5 and 6 differ from FIGURE 4 in the use of NKS and AFS, respectively, for specific inhibition. Anti-LAS contained antibodies to antigens in all these preparations, and absorption with NKS did not remove all antibodies to AFS or 
embryo antigens. Complex relationships evidently exist among the antigens of the embryo and tumor. These will be considered elsewhere. In the context of this report, it is to be noted that anti-LAS produced no lines in FIGURES 4 to 6 that can be related to line $X$ in FIGUREs 1 to 3 .

Among the various lines that formed in these patterns, line $X$ was chosen for particular attention because of its unique distribution. It was present in the normal kidney but absent from the tumor. These observations were confirmed with antisera from over 320 bleedings of five rabbits injected with NKS, eight with LAS, seven with AFS, two with LOS (large oocyte supernatant), and four with TBS. This line, whose antigen was designated antigen $X$, was formed by oocyte, tailbud, and normal kidney preparations and could be detected with antisera directed against any of these (FIGURE 7). It was not formed by AFS or LAS preparations and could not be detected with antisera directed against them. Controls using normal rabbit serum were negative.

Similar tests were run in immunoelectrophoresis using both absorbed and unabsorbed antisera (FIGURES 10 to 13 ). These tests confirmed the agar diffusion data, but also revealed that line $X$ had a mobility that suggested an isoelectric point of the order of $p \mathrm{H} 10.5$.

The antigen of line $\mathrm{X}$. In considering the identity of antigen $X$, most of the known basic proteins, including histone, ${ }^{36}$ were eliminated from first consideration because they are not sufficiently basic or are poor antigens. Also, the failure of the line to stain with Sudan black ${ }^{27}$ demonstrated that the antigen was not a lipoprotein. We suspected either lysozyme or avidin, both of which are highly basic. The former is known to be antigenic, ${ }^{2, .29}$ while we found no reports of the antigenicity of the latter.

To test this hypothesis, normal kidney, tailbud embryos, and mature ovaries were subjected to the fractionation procedure for avidin and lysozyme. Agar diffusion tests of these fractions revealed that the antigen of line $X$ followed the "Iysozyme" fraction (FIGURE 8 ) and that the amount of the antigen in $100 \mu \mathrm{g} . / \mathrm{ml}$. of the fraction corresponded to the amount in $10 \mathrm{mg} . / \mathrm{ml}$. of NKS (FIGURE 9 ).

Further similarity of antigen $X$ to lysozyme was demonstrated when line $X$ was formed in agar diffusion analysis by both NKS and the "Iysozyme" eluate after exposure to $98^{\circ} \mathrm{C}$. for five minutes at $p \mathrm{H} 4.0$, but not on similar exposure at $p \mathrm{H} 11.0$. Also, antigen $X$ passed through Visking casing during prolonged dialysis, suggesting relatively low molecular weight as expected for a lysozyme molecule.

Lytic activity. The physical similarities of antigen $X$ to lysozyme led to an examination of antigen $X$ for bacteriolytic activity. Spot tests of the bentonite fraction on nutrient agar cultures of $M$. lysodeikticus produced zones of growth inhibition corresponding to those produced by chicken egg white lysozyme controls. 

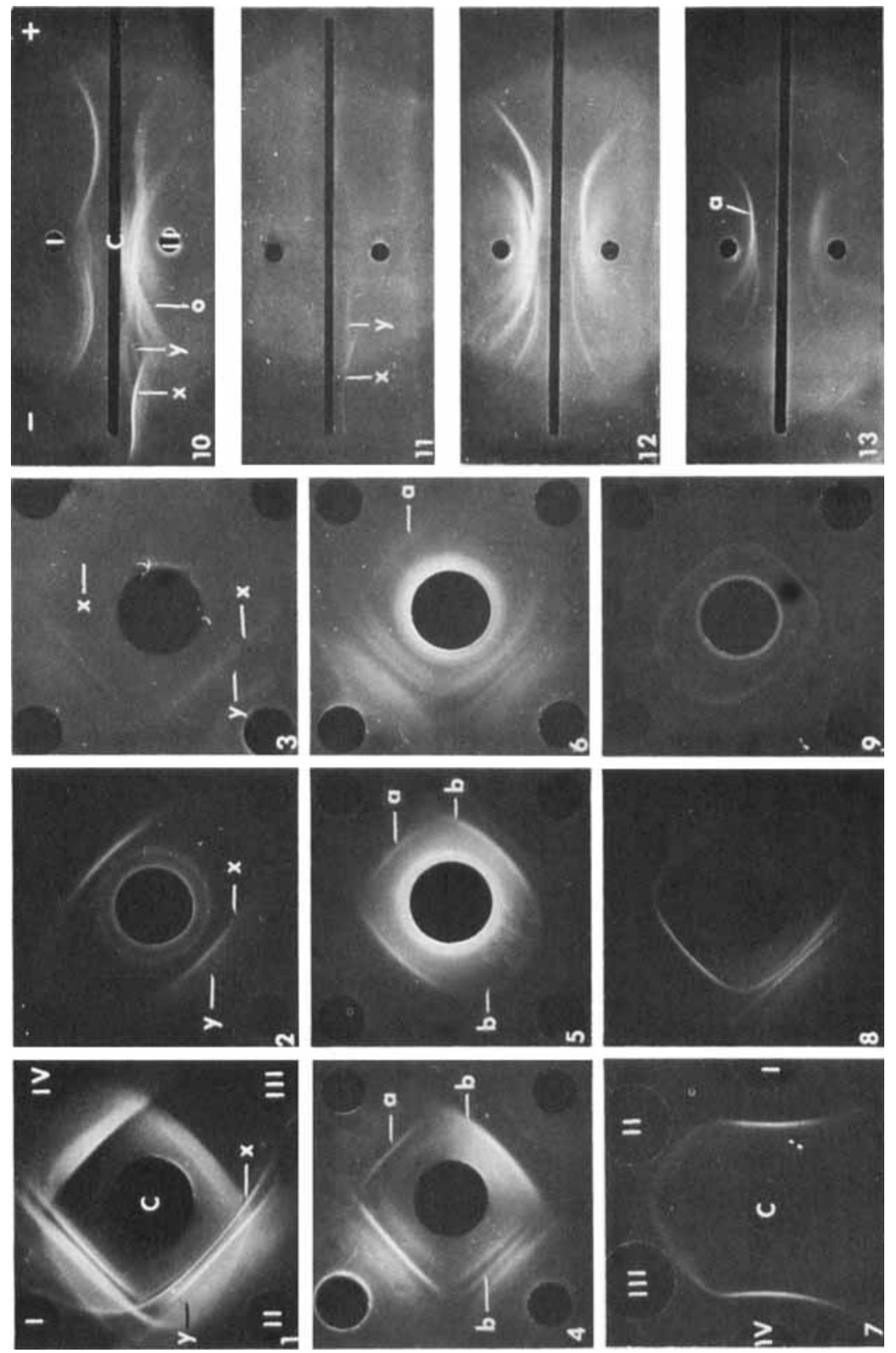

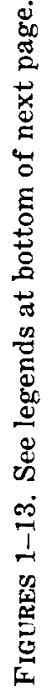




\section{Explanatory Notes for Figures 1-13}

Wells and troughs in the agar diffusion patterns are numbered as indicated in FIGURES 1, 7, and 10. The distance between the inside edges of Wells $I$ and $C$ in the original planchets were: $4 \mathrm{~mm}$. for FIGURES 1 to $9 ; 3.5 \mathrm{~mm}$. for FIGURES 10 to 13 .

Patterns were chosen for illustration on the basis of the uniform arrangement of antigens and antibodies in the wells. As far as possible, comparable patterns formed with antiserum from the same rabbit and bleeding were chosen. Different preparations of the antigens were used in every case.

Figure 1. Reactions of unabsorbed antinormal kidney supernatant. Diffusion time 120 hours. Well I - LAS (Lucké adenocarcinoma supernatant), $10 \mathrm{mg}$. P (protein) $/ \mathrm{ml}$. Well $I I-\mathrm{NKS}$ (normal kidney supernatant), $10 \mathrm{mg}$. P $/ \mathrm{ml}$. Well $I I I$ - AFS (adult frog serum), $10 \mathrm{mg}$. P/ml. Well $I V$ - TBS (tailbud supernatant), $10 \mathrm{mg}$. P/ml. Well $\mathrm{C}-\mathrm{A}$.NKS $78-12$ glob. (antinormal kidney supernatant, rabbit 78 , bleeding number 12 , globulin fraction), $39 \mathrm{mg} . \mathrm{P} / \mathrm{ml}$.

FIGURE 2. Reactions of A.NKS specifically inhibited with LAS. Diffusion time 120 hours. Wells $I-I V$ as in FIGURE 1 but using new preparations of each antigen. Well $C$ - LAS, $15 \mathrm{mg} . \mathrm{P} / \mathrm{ml}$., in well for 24 hours (Well.s $I-I V$ empty), removed and replaced by A.NKS 78-12 glob., $39 \mathrm{mg} . \mathrm{P} / \mathrm{ml}$. (Wells $I-I V$ filled).

FigURE 3. Reactions of A.NKS specifically inhibited with AFS. Diffusion time 240 hours. Wells $I-I V$ as in FIGURE 2 . Well $C-\mathrm{AFS}, 20 \mathrm{mg}$. $\mathrm{P} / \mathrm{ml}$., followed by A.NKS 78-14, glob., $17 \mathrm{mg}$. P/ml.

Figure 4. Reactions of unabsorbed A.LAS. Diffusion time 120 hours. Wells I-IV as in FIGURE 2 . Well C-A.LAS $75-41$ glob., $32 \mathrm{mg}$. P $/ \mathrm{ml}$.

Figure 5. Reactions of A.LAS specifically inhibited with NKS. Diffusion time 120 hours. Wells $I-I V$ as in Figure 2 . Well $C-$ NKS, $14 \mathrm{mg} . \mathrm{P} / \mathrm{ml}$., followed by A.LAS $115-11$ glob., $20 \mathrm{mg}$. P $/ \mathrm{ml}$.

Figure 6. Reactions of A.LAS specifically inhibited with AFS. Diffusion time 168 hours. Wells $I-I V$ as in FIGURE 2 . Well $C-$ AFS, $20 \mathrm{mg}$. P $/ \mathrm{ml}$, followed by A.LAS $75-41$ glob., $32 \mathrm{mg}$. $\mathrm{P} / \mathrm{ml}$.

FIGURE 7. Comparison of several absorbed antisera. Diffusion time 96 hours. All antisera absorbed to completion in vitro. Well I - A.LOS 70-13 glob. (large oocyte supernatant), $23 \mathrm{mg}$. P/ml. absorbed with LAS. Well $I I-\mathrm{A} . \mathrm{NKS} 78-17$, $15 \mathrm{mg} . \mathrm{P} / \mathrm{ml}$. absorbed with normal liver supernatant. Well $I I I-$ A.NKS $78-17$, $15 \mathrm{mg}$. P $/ \mathrm{ml}$. absorbed with LAS. Well IV-A.TBS 80-7, $28 \mathrm{mg}$. P $/ \mathrm{ml}$. absorbed with LAS. Well $C-\mathrm{NKS}, 10 \mathrm{mg}$. P $/ \mathrm{ml}$.

FIGURE 8. Comparison of bentonite extracts of mature ovary with NKS. Diffusion time 120 hours. Well I - Extract 5 ("lysozyme") $0.1 \mathrm{mg}$. P/ml. Well II - NKS, $10 \mathrm{mg}$. P $/ \mathrm{ml}$. Well $I I I$ - Extract $3,1 \mathrm{mg}$. P $/ \mathrm{ml}$. Well IV - Extract 4 ("avidin") $2 \mathrm{mg} . \mathrm{P} / \mathrm{ml}$. Well C-A.NKS $78-11$ glob. $26 \mathrm{mg}$. P/ml. unabsorbed.

Figure 9. Quantification of "lysozyme." Diffusion time 72 hours. Well $I-$ "lysozyme," $10 \mu \mathrm{g} . / \mathrm{ml}$. Well $I I-\mathrm{NKS}, 10 \mathrm{mg}$. P $/ \mathrm{ml}$. Well $I I I-"$-"ysozyme," $50 \mu \mathrm{g} . / \mathrm{ml}$. Well IV- "lysozyme," $100 \mu \mathrm{g} . / \mathrm{ml}$. Well $C$-A.NKS 78-13 glob. $20 \mathrm{mg}$. P/ml. inhibited with LAS.

FIGURE 10. Immunoelectrophoresis reactions of unabsorbed A.NKS. Diffusion time 168 hours. Well $I$-LAS $10 \mathrm{mg}$. P/ml. Well $I I-\mathrm{NKS}, 10 \mathrm{mg}$. P $/ \mathrm{ml}$. Well $\mathrm{C}-\mathrm{A} . \mathrm{NKS} 78-13$ glob., $20 \mathrm{mg}$. $\mathrm{P} / \mathrm{ml}$. Veronal buffer, $p \mathrm{H} 8.6,15 \mathrm{~V} / \mathrm{cm}$., $8 \mathrm{~mA}, 45$ minutes. " $O$ " - Zero point determined with dextran. Polarity indicated by standard symbols.

FIGURE 11. Immunoelectrophoresis reactions of A.NKS absorbed with LAS in vitro. Other conditions as in FIGURE 10.

FIGURE 12. Immunoelectrophoresis reactions of unabsorbed A.LAS 75-41 glob. $32 \mathrm{mg} . \mathrm{P} / \mathrm{ml}$. Other conditions as in FIGURE 10 .

FIGURE 13. Immunoelectrophoresis reactions of A.LAS absorbed with NKS in vitro. Other conditions as in FIGURE 12. Absorption incomplete. 
Turbidimetric tests were then applied using bentonite fractions prepared from the frog ovary, tailbud, and kidney. Although the ovary and tailbud preparations contained antigen $X$, their lytic activity was low in comparison with chicken lysozyme. The kidney preparations, however, possessed lytic activity quite comparable to that of the chicken standards.

Aside from the fact that the turbidimetric procedure could not be used to identify the lytic substances in agar matrix applications, it also has not proven to be as sensitive as the intra-agar technique for the measurement of the frog lytic substances. The reasons for this are uncertain, but the differences in the patterns of lysis within the lysis discs, and the sharpness of the edges of the discs produced by the chicken and frog preparations, suggest different properties for the two types of preparations. These may be differences of substrate specificity, a point that has not yet been tested. However, that differences in their properties do exist was shown when it was found that the optimal conditions for lytic activity of at least the frog ovary preparations were $p \mathrm{H} 8.5$ and $\mathrm{NaCl} 0.85$ per cent compared with $p \mathrm{H}$ 6.2, $\mathrm{NaCl} 0.5$ per cent conditions optimal for the chicken preparations and used in the initial turbidimetric studies. The turbidimetric data obtained with these revised conditions suggested that when adequately purified the lytic activities of the frog and chicken materials will be demonstrated as essentially equivalent. The data in TABLE 1 , though collected under somewhat different conditions, support this conclusion if these data are examined within the limitations of the quantitative comparability of the chicken and frog preparations discussed in Materials and Methods.

Antigen $\mathrm{X}$ as the lytic agent. The data reported above indicate that the frog preparations: (1) have lytic activity, and (2) contain a material, antigen $X$, with physical properties resembling the lysozymes. If differs from chicken egg white lysozyme in respect to its antigenic specificity, since agar diffusion tests failed to reveal any cross reactions between the frog and chicken reagents. It may also differ from the chicken lysozyme with respect to the optimal conditions for the demonstration of the lytic activity.

That antigen $X$, and not a contaminant of the preparations, e.g., antigen " $y$ " (FIGURE 1), is the bacteriolytic component cannot be stated with certainty until further fractionation and immunochemical analyses are complete.

Some evidence for the correspondence of antigen $X$ to the lytic activity came, however, from agar diffusion tests using antisera prepared against the bentonite fraction of LOS. These tests with less complex antisera confirmed the results of tests with anti-LOS and again demonstrated the absence of antigen $X$ from the tumors, but revealed its presence in noncancerous portions of the affected kidneys. Turbidimetric tests of fractions of the same tumors also failed to show any evidence of Iytic action. In 
other tests, the heating of preparations at $p \mathrm{H} 4.0$ not only led to the retention of antigen $X$ but also of the lytic activity, whereas heating at $p \mathrm{H} 11.0$ destroyed both the antigen and the activity. Thus the absence of antigen $X$ is accompanied by the absence of the activity ascribed to it.

Attempts to demonstrate the correspondence between line $X$ and the lytic activity in intra-agar lysis applications of immunoelectrophoreses have proven, to date, somewhat disappointing because of differences in the optimal conditions for revealing precipitation lines and intra-agar lysis. Patterns currently available show that lysis occurs nearer to line $X$ than to any other lines in the patterns but the lysis is not centered on the focal point of the arc formed by the line $X$.

Attempts to inhibit lysozyme activity with antisera forming line $X$ have been unsuccessful, because the antisera to our relatively crude preparations have not been sufficiently strong to clearly differentiate between the low levels of inhibition believed to be produced by the antisera and the levels of inhibition produced by the normal sera or gamma-globulin controls."3"

Thus, all the data point to the correspondence of antigen $X$ and the lytic activity, without providing the needed definitive evidence.

Biological observations. The existence of population differences in susceptibility to the tumor led to a comparison of the bacteriolytic activity of preparations from individual frogs collected from different localities. Among the $R$. pipiens were frogs from Vermont, the usual source of the tumor; from the highly variable Wisconsin population, characterized by frogs with small tumors that appear irregularly; and from Texas-Mexico, where tumors have not yet been reported."11" In addition, tests were made on $R$. clamitans and $R$. catesbeiana, species which have not been reported to produce the tumor in nature.

Preliminary turbidimetric tests of pooled samples of five different organs revealed population differences in lytic activity for only the normal kidney. They also indicated that the lytic activity was higher in the tumor-susceptible frogs from Vermont than in the relatively tumor-resistant frogs from Wisconsin. These tests were difficult to perform with the limited supply available, could not be performed on individual frogs, and were therefore repeated and extended using the intra-agar lysis technique.

FIGURE 14 shows an intra-agar lysis plate to illustrate the test system. Figure 15 shows a plot of the diameters of the lysis dises produced by standard dilutions of chicken egg white lysozyme. The units of activity used to compare the frog populations are discussed under Materials and Methods.

TABLE 1 presents the data from intra-agar lysis tests of kidney preparations. Data for the sexes are pooled because their average values were not significantly different, although the Vermont males showed a greater stand- 
ard deviation than did the females. Tumors showed low activities that could be explained on the basis of normal tissues within the tumor masses. $R$. clamitans and $R$. catesbeiana showed relatively low activities.

One major observation was that the average lytic activity of frogs from the tumor-susceptible Vermont population was markedly lower than that of the relatively tumor-resistant Wisconsin population. Also, the variation in activity levels among individuals newly obtained from nature was less for the Vermont population than it was for the Wisconsin population, which shows high genetic variability as indicated by the occurrence there of numerous color pattern variants.

Another major observation held true for all the populations : Active summer frogs showed higher lytic activities than did frogs entering hibernation, and this was paralleled by the observation that frogs collected in October but held in the laboratory until November showed elevated activity if kept at $25^{\circ} \mathrm{C}$., but lower activity after transfer to $4^{\circ} \mathrm{C}$. for some days. These observations explained the higher lytic activities obtained for the

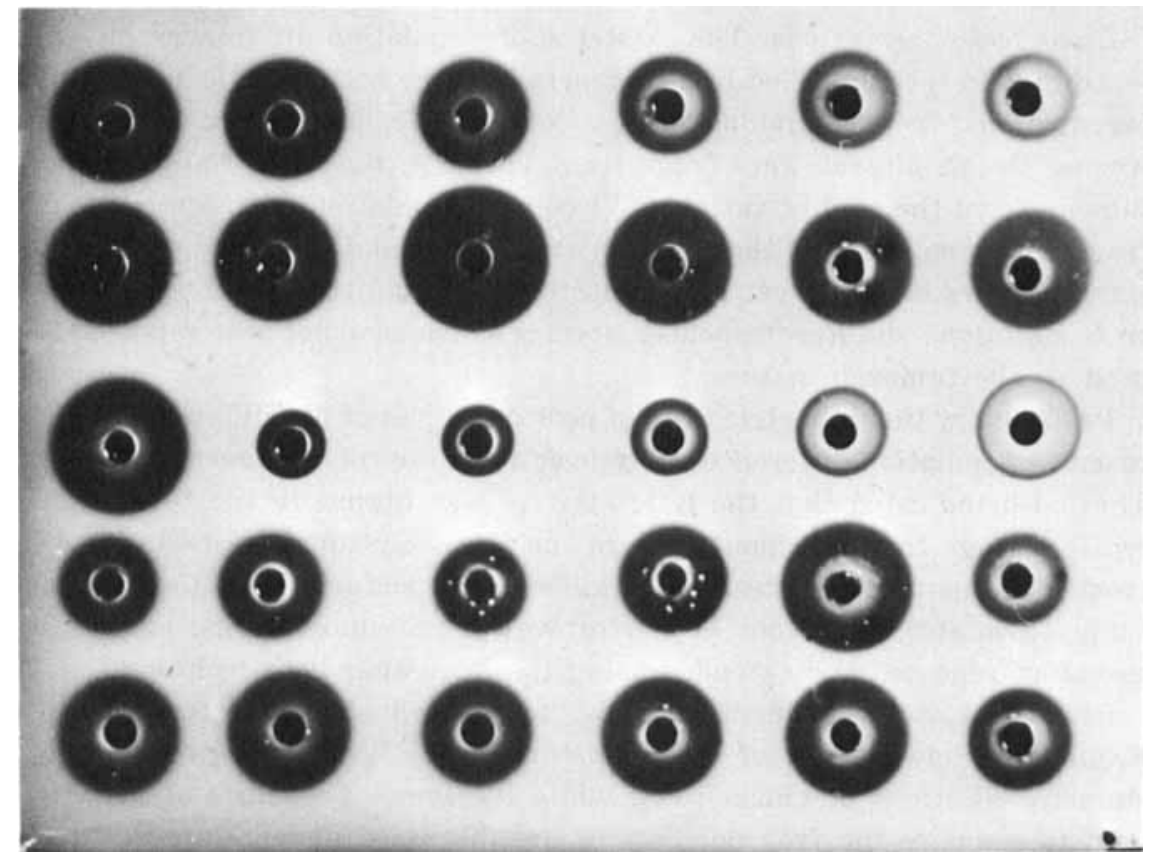

Figure 14. Intra-agar lysis tests. Measured quantities of kidney extracts from individual frogs randomly selected from the several populations were placed in each well. At least two extracts used in a prior test were introduced to assure comparability. The five wells to the right in the center row contained the standard dilutions plotted in FIGURE 15. 


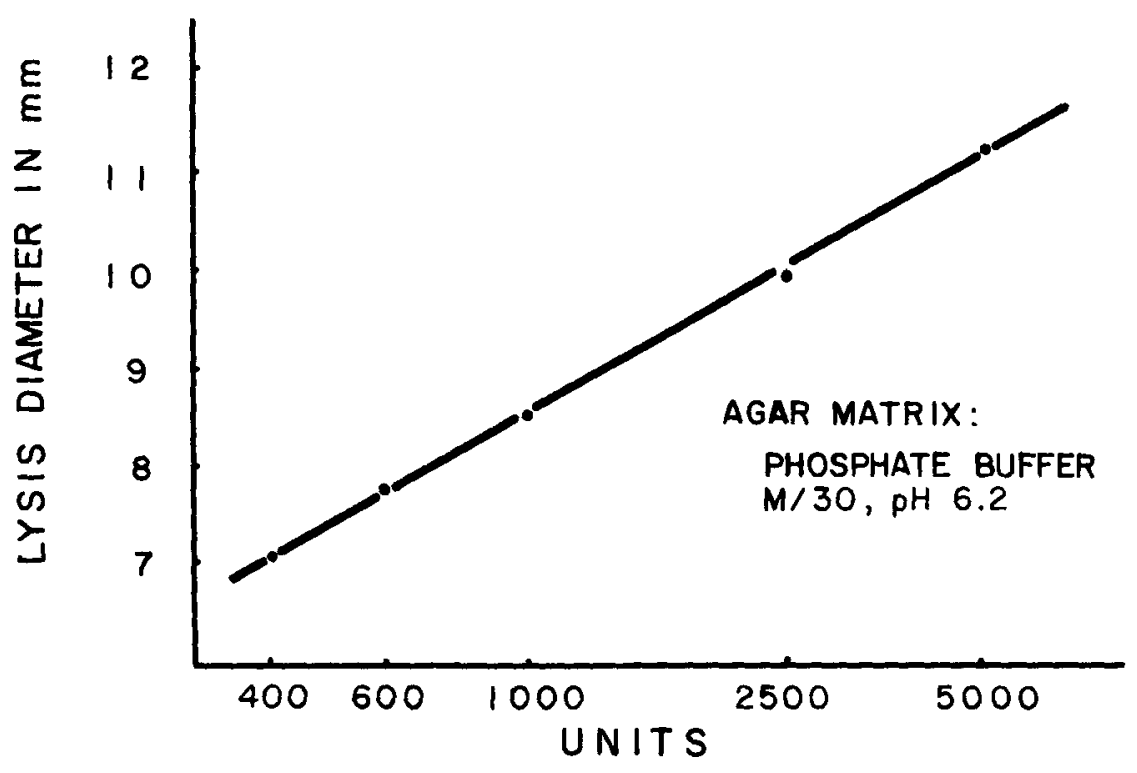

\section{UNITS = I mg. CHICKEN LYSOZYME}

FIGURe 15. Intra-agar lysis. Chicken Iysozyme standard.

Vermont frogs in the preliminary turbidimetric assays. These tests had compared summer Vermont frogs with winter Wisconsin frogs, thus resulting in the apparent reversal of the relationships expected on the basis of concepts discussed below.

Sera were also compared, but in all cases yielded average values of less than 100 units with standard deviations higher than the average values. The sera of many individuals failed to show any lytic activity. There was no evidence that individuals with high lytic activities for the kidney extracts were the ones that showed the serum activities.

These results indicate at least quantitative species specificity for this lytic activity. They indicate that there is a higher lytic activity for normal kidney extracts of frogs from the relatively tumor-resistant (Wisconsin) than from the tumor-susceptible (Vermont) populations from the same type of climate. Also, they show that there is a marked reduction of activity between summer and winter; further, that the Wisconsin population that produces few tumors shows greater variation within the population.

\section{Discussion}

Two premises guided this investigation: first, that macromolecular composition can be used to characterize specific differentiation states $;^{1,2,6,15,31,3: 2}$ 
second, that no a priori grounds exist for anticipating which macromolecules will characterize specific differentiation states. Thus, broad techniques, such as those provided by initial immunochemical survey using complex reagents, are needed to identify macromolecules characterizing a differentiation state. These premises were validated by the discovery of antigen $X$, by the demonstration that it distinguishes the normal from the tumor kidney, and by the evidence for its lytic function. That such a molecule could not be predicted as a component distinguishing these differentiation states in the frog is evident, since the only pertinent reference:3: reported the absence of lysozyme from amphibian serum.

Evidence is presented indicating that antigen $X$ possesses many of the physical properties of lysozyme and that preparations containing antigen $X$ possess lytic activity resembling that of lysozyme. However, definitive evidence for the identity of antigen $X$ and the lytic factor is still lacking. If they should not prove to be identical, then the normal kidney may be distinguished from the tumor by an additional macromolecule.

The evidence for a lytic factor in the frog suggested its similarity to chicken egg white lysozyme in many ways, but several lines of evidence were also presented suggesting differences. Thus, it can only be described as a lysozyme-like enzyme, since the precise catalytic action of the frog lytic factor has not yet been elucidated.

The evidence presented here for an antigenic loss associated with the neoplastic process agrees with many observations of recent years.3-5.34 However, the interpretations of such antigenic losses are many and, in general, have not been related to specific functional properties of the antigens in question. Therefore, the significance of the observations reported here cannot be related to the significance of these other antigenic losses in any precise manner. The case of the antigen loss reported by Barch $^{34}$ to be associated with the neoplastic transformation in the frog is a case in point. Her antigen is water soluble, present in the kidney and absent from the tumor and other organs, but no functional role can be attributed to it. It is not antigen $X$ because antigen $X$ is not kidney specific. Nevertheless, the discovery of lytic activity as a functional property associated with antigen $X$ and the several observations relating antigen $X$ and the lytic activity to biological aspects of the renal adenocarcinoma demand some examination. This examination becomes most pertinent in view of the several reports ${ }^{3:-3 x}$ of lysozyme changes associated with neoplastic processes, although the changes described in these reports on mammals cannot be directly related to the case of the frog renal adenocarcinoma.

First, it must be recalled that much evidence has accumulated to support the concept of a viral etiology for the frog renal adenocarcinoma. ${ }^{3,1}$ The major difficulties confronting this hypothesis are the high spontaneous rate of tumor formation, the quantitative rather than qualitative effect of 
injected extracts, and the absence of rigorous and direct demonstration of a causative virus. ${ }^{10}$ Second, a considerable body of literature exists on the possible antiviral activity of lysozyme. ${ }^{3:-11}$

These two hypotheses can profitably be examined in conjunction with the observations reported here on the biology of the lytic factor in the frog, and with the life cycle of the Lucké tumor virus suggested by Rafferty." This life cycle suggests that viral infection occurs during embryonic or larval development; that postmetamorphic frogs are refractory; that the virus remains dormant until the third or later summer when small tumors appear; that during the following hibernation, tumor growth ceases, but virus production increases; and that characteristic nuclear inclusions and virus disappear on emergence from this hibernation, followed by rapid tumor growth during the terminal summer. Less clear is the biology of the noninclusion tumors that develop when "normal" frogs are maintained in the laboratory.

The cycle and the observations on which it is based can be readily explained if the lytic factor demonstrated here proves to possess antiviral activity as is claimed for lysozyme. ${ }^{: 1-11}$ If so, low lytic activity would be associated with susceptibility to viral infection and vice versa.

We have noted that the egg and larvae of the frog contain the lytic factor, but have indicated that at these stages the activity is at a low level. Thus, infection could occur at these stages. In normal summer frogs the lytic activity reaches its peak, and the frogs would be refractory to infection and, if harboring a low-level infection, could presumably clear themselves of all but residual numbers of virus. In the winter the lytic activity drops to a minimum, and defense against the virus would become minimal. Original infection might well occur at that time in the crowded conditions of lake bottom hibernation prevailing in such localities as Lake Champlain, the major source of the tumors, or multiplication of residual virus could take place. This would be facilitated by the absence of antibody production characterizing hibernating frogs or frogs held at low temperature. ${ }^{4-14}$ The advanced age of the frogs when the first evidence of the pathology is seen could be explained by late infection in a year when the frog's lytic factor reached a particularly low level, or by a three-year requirement for the production of pathogenic quantities of the virus. Presumably, the number of residual viruses surviving through the summer would increase each year, and, concurrently, the ability of the kidney to produce the lytic factor would decrease as damage produced by the virus increased. This would result in maximal virus production during hibernation following the summer when the kidneys had been so damaged as to reduce the production of the lytic factor below a critical level. This damage is indicated by the small tumors observed at the end of that summer. The failure of virus production in the terminal summer, after the 
virus bloom, when tumor growth is maximum and lytic factor is absent, can be explained on the basis of antibody released in these warm months and conferring summer immunity as described by Bisset. $+2+3$

The formation of tumors in laboratory frogs held at elevated temperatures could be explained as an acceleration of the consequences of prior damage produced by the virus, resulting in the suppression of lytic factor production. The failure of viral multiplication in these frogs would be explained on the basis of the immunity suggested above.

Our data suggest marked differences in the lytic activity of different frogs in a given population. Presumably, only those with activity levels at the lower range would be susceptible either to the viral infection, to the normal course of infection, or to tumor formation under laboratory conditions. This would explain the erratic results obtained following the injection of extracts, and one might predict that preliminary biopsy assay for lytic activity could result in the selection of individuals susceptible to the injection.

Similar explanations could be made for the differences between populations. The susceptible frogs would appear most regularly in the Vermont population, which has a Iower average level of lytic activity than the Wisconsin population. However, the high variability of the Wisconsin frogs would always result in the presence of a small number of susceptible animals and in some years would result in increased numbers of such individuals.

The refractoriness of the Texas-Mexico frogs could be related to their failure to undergo hibernation and, thus, to the failure of their lytic levels to fall sufficiently; the absence of the tumor in other species could be related to genetic factors.

\section{Summary}

(1) Antigens of normal R. pipiens kidneys were compared with those of the frog renal adenocarcinoma. Among others, an antigen, designated antigen $X$, was found in the normal, but not the tumor kidneys.

(2) The physical properties of antigen $X$ led to the suggestion that it might be a lysozyme. Preparations containing the antigen were then found to possess lytic activity. However, the identity of antigen $X$ with the lytic factor has not yet been confirmed. Differences between this lytic factor and chicken egg white lysozyme suggest that, though the resemblance is strong, the frog factor can at present only be designated as a lysozymelike substance.

(3) Using a new intra-agar assay procedure, the lytic activity was demonstrated to be higher in a relatively tumor-resistant population of frogs (Wisconsin) than in a tumor-susceptible population (Vermont). Also, it was shown to be higher in summer frogs or in frogs maintained at ele- 
vated temperatures than in hibernating or chilled frogs. $R$. pipiens from Texas-Mexico had relatively low levels of the lytic factor but may not be subjected to further reduction of this level because of their failure to hibernate. $R$. clamitans and $R$. catesbeiana had lower levels of activity than did $R$. pipiens.

(4) These observations on the lytic factor have been related to a suggested life cycle of the frog tumor virus in an effort to elucidate several aspects of the etiology of the renal adenocarcinoma.

\section{Acknowledgments}

Thanks are due to Mr. Jack Hegenauer, Mrs. Marie Coon, and Mrs. Diane Ar for their technical assistance throughout the course of this study, and to Dr. Yasuji Amano for his professional assistance in the later phases of the work.

\section{References}

1. EBert, J. D. 1959. The acquisition of biological specificity. In The Cell. I. J. Brachet \& A. E. Mirsky, Eds. : 619-693. Academic Press, New York, N. Y.

2. Flickinger, R. A. 1962. Embryological development of antigens. Advan. Immunol. 2: 309-366.

3. GreEN, H. N. 1959. Immunological aspects of cancer. In Carcinogenesis: Mechanisms of Action. Ciba Foundation Symp. : 131-160.

4. Tumor Immunity. 1962. D. B. Amos \& C. A. Stetson, Jr., Conference Cochairmen. Ann. N. Y. Acad. Sci. $101: 1-362$.

5. CONCEPTUAL ADVANCES IN IMMUNOLOGY AND ONCOLOGY. 1963. A collection of papers presented at the Sixteenth Ann. Symp. Fundamental Cancer Res. 1962. Univ. Texas N. D. Anderson Hospital and Tumor Inst. Houston, Tex.; Harper \& Row, Publishers, Inc. New York, N. Y.

6. NACE, G. W. 1955. Development in the presence of antibodies. Ann. N. Y. Acad. Sci. 60: 1038-1055.

7. Nace, G. W., T. Suyama \& N. Smith. 1961. The development of special proteins. In Germ Cells and Earliest Stages of Development. Symp. I.I.E.-Pallarza. 1960. S. Ranzi, Ed. : 564-603.

8. NACE, G. W. \& LORA H. LAvin. 1963. Heterosynthesis and autosynthesis in the early stages of anuran development. Am. Zoologist 3: 193-207.

9. Viral Diseases of Poikilothermic Vertebrates. 1965. S. F. Snieszko, R. F. Nigrelli \& K. E. Wolf, Conference Cochairmen. Ann N. Y. Acad. Sci. This Annal.

10. RAFFerTy, JR., K. A., 1964. Kidney tumors of the leopard frog: A review. Cancer Res. 24: 169-186.

11. NACE, G. W. 1961. Antigenic characterization of frog kidney adenocarcinoma. Transcript Proc. Frog Kidney Adenocarcinoma Conf. Natl. Cancer Inst. : 91-98. Bethesda, Md.

12. NACE, G. W. 1962. Discussion. In Symposium on specificity of cell differentiation and interaction. J. Cell. Comp. Physiol. Suppl. 1. 60:61.

13. NACE, G. W. \& T. SuYama. 1964. The loss of a bacteriolytic enzyme associated with the appearance of a frog kidney tumor. SABCO J. 1(2): 1-5. (In Japanese).

14. NACE, G. W. \& K. Inoue. 1957. Cytolysis versus differentiation in antineurula serum. Science 126: 259-261. 
15. NACE, G. W. \& W. M. ClaRk. 1958. Immunohistological localization of one or more transitory antigens in the optic cup and lens of Rana pipiens. In Symposium on the Chemical Basis of Development. McElroy \& Glass, Eds. : 546-561. McCullum-Pratt Inst. The Johns Hopkins Press. Baltimore, Md.

16. Alderton, G., W. H. Ward \& H. L. Fevold. 1945. Isolation of lysozyme from egg white. J. Biol. Chem. $157: 43-58$.

17. NaCE, G. W. \& P. SPRadlin. 1962. Bleeding rabbits. Turtox News 40: 26-29.

18. NACE, G. W. \& J. ALLEY. 1961. On the photography of unstained, differentially stained and fully stained precipitin lines in agar. J. Biol. Photo. Assoc. 29: 125-133.

19. SCHEIDEGGER, J. J. 1955. Une micromethode de l'immunoélectrophorese. Intern. Arch. Allergy 7 : 103-110.

20. BJöRKLUND, B. 1952. Specific inhibition of precipitation as an aid in antigen analysis with gel diffusion method. Proc. Soc. Exptl. Biol. Med. 79: 319324.

21. Smolelis, A. N. \& S. E. Hartsell. 1949. The determination of lysozyme. J. Bacteriol. 58: 731-736.

22. Lobstein, O. E. \& S. J. Fogelson. 1951. The effect of chloride concentration on the determination of lysozyme activity. Am. J. Dig. Dis. 18: 298-299.

23. Analytical Microbiology. 1963. F. Kavanagh, Ed. Academic Press. New York, N. Y.

24. Amano, T. 1962. Rizochimu no meneki kagakuteki kenkyu (Immunochemical study of lysozyme). Tanpakushitsu kakusan kōso (Protein, nucleic acid, enzyme) 7:697-704. (In Japanese).

25. Tallan, H. H. \& W. H. SteiN. 1953. Chromatographic studies on lysozyme. J. Biol. Chem. 200: 507-514.

26. Horn, E. C. 1962. Extranuclear histone in the amphibian oocyte. Proc. Natl. Acad. Sci. (U.S.) 48: 257-265.

27. UrIeL, J. \& P. Grabar. 1956. Emploi de colorants dans l'analyse électrophorétique et immunoélectrophorétique en milieu gélifié. Ann. Inst. Pasteur 90: 427-440.

28. FuJio, H., S. Kishiguchi, S. Shinka, Y. Saiki \& T. Amano. 1959. Immunochemical studies of lysozyme. I. Comparative studies of lysozyme and lysozyme methyl ester. Biken J. 2: 56-76.

29. Smolens, J. \& J. Charney. 1947. The antigenicity of crystalline lysozyme. J. Bacteriol. 54: 101-107.

30. Shinka, S., M. Imanishi, O. Kuwahara \& T. Amano. 1962. Immunochemical studies on lysozyme. II. On the nonneutralizing antibodies. Biken J. 5: 181-200.

31. FlickiNGer, R. A. \& G. W. NACE. 1952. An investigation of proteins during the development of the amphibian embryo. Exptl. Cell Res. 3: 393-405.

32. OKAdA, T. S. \& A. G. SATo. 1963. Soluble antigens in microsomes of adult and embryonic kidneys. Exptl. Cell Res. $31: 251-265$.

33. Caselli, P. \& N. Melucci. 1947. Activita lisozimica del siero di sanque di mammiferi, uccelli, rettili, anfibi e pesci. Boll. Soc. Ital. Biol. Sper. 23: $568-569$.

34. Barch, Stephanie E. 1962. Comparison of antigenic components in normal and neoplastic tissues. Exptl. Cell Res. $27: 548-552$.

35. Ottaviani, A. 1959. Richerche elettroforetiche sol lisozima negli estratti di linfoghiandole normali e di linfoghiandole sede di metastasi tumorali. First Intern. Symp. Fleming's Lysozyme (Milan) : 207-209.

36. Symposium on Lysozyme as Related to Problems in Microbiology. 1960. S. E. Hartsell, Ed. : 36 . Soc. Am. Bacteriol.

37. Perri, G. C., M. Faulk, J. Mellors \& C. C. Stock. 1962. Crystallization of a basic protein (lysozyme) from kidneys of tumor-bearing rats (Jensen sarcoma). Nature 193: 649-651. 
38. Lobstein, O. E., S. I. Dulkin \& E. O. Bierman. 1959. Lysozyme in Gardner's lymphosarcoma in mice. First Intern. Symp. Fleming's Lysozyme (Milan) : $210-215$.

39. Ferrari, R., C. Callerio \& G. Podio. 1959. Antiviral activity of lysozyme. Nature 183: 548 .

40. II ${ }^{n}$ Sezione: Lisozima ed Infezioni da Virus. 1959. First Intern. Symp. Fleming's Lysozyme (Milan).

41. II Sezione: Lisozima E VIRosi. 1961. Second Intern. Symp. Fleming's Lysozyme (Milan).

42. BISSET, K. A. 1947. Bacterial infection and immunity in lower vertebrates and invertebrates. J. Hyg. 45: 128-135.

43. BisseT, K. A. 1948. Natural antibodies in the blood serum of fresh-water fish. J. Hyg. 46: 267-268.

44. Austin, L. G., G. W. NACE \& L. H. Lavin. Unpublished results. 